\title{
ESCOLA TÉCNICA, CONHECIMENTO INTEGRADO E POLITECNIA
}

\author{
ESCUELA TECNICA, CONOCIMIENTO Y POLITECNIA
}

Ione dos Santos Rocha

Instituto Federal de Educação, Ciência e Tecnologia Baiano; Grupo de Estudos de Ideologia e Lutas de Classes (GEILC/CNPQ).

José Rubens Mascarenhas de Almeida

Universidade Estadual do Sudoeste da Bahia. Coordenador do GEILC/Museu Pedagógico da UESB e pesquisador do NEILS (Núcleo de Estudos de Ideologia e Lutas Sociais/PUC-SP).

\section{Resumo}

$\mathrm{O}$ artigo aqui apresentado objetiva discutir a trajetória das escolas técnicas brasileiras diante da proposição de ensino integrado da legislação vigente e aprofunda a discussão acerca da politecnia como proposta de superação da dualidade entre trabalho intelectual e manual. A partir deste objetivo, são analisadas as contradições, desde o surgimento à distribuição, das instituições públicas de ensino técnico e a trajetória do estabelecimento desta rede de ensino até a atualidade, retratando a apropriação política da educação como mecanismo de promoção das demandas econômicas. Nesse sentido, o debate acerca do conceito de politecnia, que corresponde a uma concepção de educação mais profunda a partir da apropriação da tecnologia como conhecimento e produção social, é um desafio dos cursos técnicos integrados em vigor nas escolas atuais.

Palavras-chave: Ensino integrado. Escola técnica. Politecnia 


\begin{abstract}
Resumen
El artículo que aquí se presenta tiene como objetivo discutir la trayectoria de las escuelas técnicas brasileñas en la proposición de enseñanza integrada de la legislación vigente y profundiza la discusión de la Politécnica como una propuesta para superar la dualidad entre el trabajo intelectual y manual. A partir de este objetivo, las contradicciones son analizadas ya que la distribución apariencia, las instituciones públicas de enseñanza técnica y la trayectoria de la creación de este sistema escolar hasta la actualidad, que representan la implicación política de la educación como mecanismo de promoción de demandas económicas. En este sentido, el debate sobre el concepto de la Politécnica, que corresponde a una concepción de la educación más profunda de la apropiación de la tecnología como el conocimiento y la producción social, es un desafío de cursos técnicos integrados en vigor en las escuelas de hoy.
\end{abstract}

Palabras clave: Enseñanza integrada. Escuela técnica. Politécnicas.

\title{
1- Introdução
}

Os últimos dezesseis anos da história do Brasil registram mudanças nas políticas educacionais que incluem a difusão do ensino técnico e superior. Tal difusão se dá no entrelaçamento dos ditames político-econômicos do desenvolvimento tecnológico com vistas ao crescimento econômico do país. A trajetória histórica das instituições públicas de ensino profissionalizante, entretanto, é atravessada pelas contradições políticas que caracterizam Estado e sociedade capitalista, dentre as quais se destaca a vinculação da educação profissional aos interesses de mercado, quando reproduz a cisão entre os trabalhos intelectual e manual.

$\mathrm{Na}$ atualidade, os Institutos Federais são as instituições que abarcam a educação profissionalizante na rede pública brasileira, incorporando o ensino médio integrado ao técnico, cursos subsequentes, e cursos superiores especialmente voltados para as ciências exatas e engenharias. Diante desse quadro, as referidas instituições vivenciam a contradição que agora parece ampliada, pois não se trata apenas da tradição do paradigma tecnicista amplamente combatido no passado. Em suas propostas político-pedagógicas contemporâneas, essas instituições definem como missão institucional a formação do "cidadão históricocrítico" (IFBA, 2013). É justamente neste sentido que a possibilidade da educação politécnica Revista RBBA 
se apresenta para estas instituições, embora o debate seja profundo, envolvendo uma avaliação da trajetória histórica da educação profissionalizante no Brasil e requeira, principalmente, a superação do paradigma tecnicista que ainda permeia o currículo e as práticas educacionais.

\section{2- Trajetória da educação profissionalizante no âmbito das escolas técnicas brasileiras}

A implantação da rede de escolas técnicas no Brasil iniciou-se com as escolas de aprendizes artífices criadas pelo Decreto Federal № . 7.566, assinado pelo presidente Nilo Peçanha, em 23 de setembro de 1909. Na definição do Ministério da Educação (MEC, 2017) essas escolas

[...] tinham o objetivo de oferecer ensino profissional primário e gratuito para pessoas que o governo chamava de "desafortunadas" à época. Essas escolas pioneiras, portanto, tinham uma função mais voltada para a inclusão social de jovens carentes do que propriamente para a formação de mão de obra qualificada. Naquele momento, a economia do País era baseada na atividade rural e, mesmo nos principais centros urbanos, o processo de industrialização ainda ocorria de maneira lenta e precária.

De acordo com a citação, na origem das escolas técnicas brasileiras, já é possível encontrar mecanismos de reprodução social. A proposta de "inclusão" desses "desafortunados", apresentada nas informações do MEC, baseava-se na oferta de formação profissional, a fim de que o público destas instituições fosse inserido na produção como classe trabalhadora, com vistas a atender aos anseios político-econômicos do desenvolvimento urbano-industrial brasileiro. Informações do Instituto Federal de Educação, Ciência e Tecnologia da Bahia (2013) reforçam que as Escolas de Aprendizes Artífices eram "voltadas prioritariamente à educação das classes mais pobres". Não obstante, a implantação social e territorialmente seletiva dessas instituições atendeu, inicialmente, à chamada "região geoeconômica concentrada"1 que corresponde, em maior parte, ao Sudeste do Brasil. Só recentemente, a partir da década de 1990, quando se verifica o processo de desconcentração ${ }^{2}$ urbano-industrial é que a rede das escolas técnicas se amplia para as cidades médias e áreas metropolitanas das demais regiões do Brasil.

O quadro a seguir mostra o processo de implantação de Escolas técnicas de 1909 a 2014, revelando períodos de plena adoção, estagnação e contextos de apropriação política dessa rede de ensino. Com base nos dados do quadro, é possível estabelecer uma relação entre 
a consolidação de políticas de desenvolvimento econômico e a expansão da rede de escolas técnicas no Brasil.

Quadro 1. Implantação de escolas técnicas no Brasil

\begin{tabular}{|c|c|c|c|}
\hline PRESIDENTE & PERÍODO & $\begin{array}{l}\text { QUANTIDADE } \\
\text { DE } \\
\text { INSTITUIÇÕES }\end{array}$ & $\begin{array}{l}\text { VINCULAÇÃO ÀS } \\
\text { UNIVERSIDADES }\end{array}$ \\
\hline Nilo Peçanha & 1909 a 1910 & 21 & 1 Escola Vinculada à UFRGS \\
\hline Hermes da Fonseca & 1910 a 1914 & 1 & \\
\hline Wenceslau Braz & 1914 a 1918 & 1 & \\
\hline Delfim Moreira & 1918 a 1919 & 1 & \\
\hline Epitácio Pessoa & 1919 a 1922 & 1 & \\
\hline Arthur Bernardes & $1922-1926$ & 2 & 1 Escola Vinculada à UFRGS \\
\hline Getúlio Vargas & $\begin{array}{l}1930-1945 \mathrm{e} \\
1951-1954\end{array}$ & 14 & $\begin{array}{l}5 \text { Escolas vinculadas às } \\
\text { Universidades Federais UFPB, } \\
\text { UFF, UFRPE, UFV E UFRJ }\end{array}$ \\
\hline Gaspar Dutra & $1946-1951$ & 11 & $\begin{array}{l}2 \text { Escolas Vinculadas às } \\
\text { Universidades Federais UFMG, } \\
\text { UFRN }\end{array}$ \\
\hline Café Filho & $1954-1955$ & 4 & $\begin{array}{l}3 \text { Escolas Vinculadas às } \\
\text { Universidades Federais UFPI, } \\
\text { UFSC, UFRN }\end{array}$ \\
\hline Juscelino Kubitschek & $1956-1961$ & 4 & $\begin{array}{l}1 \text { Escola Vinculada à } \\
\text { Universidade Federal UFSM }\end{array}$ \\
\hline João Goulart & $1961-1964$ & 6 & $\begin{array}{l}2 \text { Escolas Vinculadas às Univer- } \\
\text { sidades Federais UFRN E UFPA }\end{array}$ \\
\hline Castelo Branco & $1964-1967$ & 4 & $\begin{array}{l}2 \text { Escolas Vinculadas às Univer- } \\
\text { sidades Federais UFMG e UFSM }\end{array}$ \\
\hline Costa e Silva & $1967-1969$ & 9 & $\begin{array}{l}4 \text { Escolas Vinculadas às } \\
\text { Universidades Federais UFMA, } \\
\text { UFPI, UFSM E UFMG }\end{array}$ \\
\hline Emílio Garrastazu Médici & $1969-1974$ & 3 & $\begin{array}{l}3 \text { Escolas Vinculadas às Univer- } \\
\text { sidades Federais UFF, UFU e } \\
\text { UFPB }\end{array}$ \\
\hline Ernesto Geisel & $1974-1979$ & 1 & $\begin{array}{l}1 \text { Escola Vinculada à } \\
\text { Universidade Federal UFPI }\end{array}$ \\
\hline João Batista Figueiredo & $1979-1985$ & 2 & $\begin{array}{l}1 \text { Escola Vinculada à } \\
\text { Universidade Federal UFCG }\end{array}$ \\
\hline José Sarney & $1985-1990$ & 13 & $\begin{array}{l}2 \text { Escolas Vinculadas às Univer- } \\
\text { sidades Federais UFRR e UFTM }\end{array}$ \\
\hline Fernando Collor de Mello & $1990-1992$ & 3 & \\
\hline Itamar Franco & $1992-1995$ & 27 & 1 Escola Vinculada à UFPA \\
\hline $\begin{array}{l}\text { Fernando Henrique } \\
\text { Cardoso }\end{array}$ & $1995-2003$ & 11 & \\
\hline
\end{tabular}




\begin{tabular}{|l|l|c|l|}
\hline Luiz Inácio Lula da Silva & $2003-2010$ & 240 & \\
\hline Dilma Rousseff & $2010-2014$ & $208^{*}$ & 1 Instituto Vinculado à UFOBA \\
\hline
\end{tabular}

Fonte: Ministério da Educação (<http://blog.planalto.gov.br> Acesso em Abril de 2013).

Organização: Ione Rocha

Conforme as informações do quadro 1, a partir da década de 1930 até o fim dos anos 1960, verifica-se uma intensa atividade no sentido de implantar novas escolas vinculadas às universidades. O período pós 1964 marca certa diminuição no número de escolas técnicas implantadas, mas não a sua abolição.

Desde o início da educação profissional do Brasil buscou-se, historicamente, acompanhar o desenvolvimento das forças produtivas, contribuindo para a reprodução sistêmica do capital através da apropriação da educação. De acordo com informações do Instituto Federal Catarinense (IFC, 2013): “Em 1937, foram criados os Liceus Profissionais, em 1949, as Escolas Industriais e Técnicas e, 10 anos depois, as Escolas Técnicas”. Segundo a mesma fonte, na década de 1970, em face do processo de industrialização e urbanização, as então escolas técnicas passam a se chamar Centros Federais Tecnológicos na busca de melhor se adequarem às demandas do contexto econômico, oferecendo cursos relacionados à produção industrial e ao manejo de novas tecnologias.

A maioria das escolas técnicas implantadas desde o decreto de Nilo Peçanha estava vinculada às universidades, apontando para a apropriação político-econômica da efetiva relação entre a ciência e técnica e, assim, submetendo a produção do conhecimento e o manejo das tecnologias aos anseios do capital. Tal processo explicita o caráter de classe do Estado burguês que representa os interesses privados do capital, condicionando até mesmo direitos sociais ao institucionalizar tais demandas nas diretrizes educacionais.

A implantação das escolas técnicas continuou (ainda que em menor intensidade) entre os anos 1964 e 1985 denotando a dissimulação de um Estado que, na análise de Ferreira Jr. (2010, p. 98), “ao mesmo tempo em que suprimiam as liberdades democráticas e instituíam instrumentos jurídicos de caráter autoritário e repressivo, levavam à prática os mecanismos de modernização do Estado nacional". Esse projeto "desenvolvimentista" se torna muito mais contraditório no contexto da educação brasileira e da "racionalidade" técnica proposta pelos governos militares, em um cenário de periferia do capitalismo.

De acordo com a crítica de Ferreira Jr. (2010) a já referida "racionalidade" técnica marca, efetivamente, a consolidação de uma sociedade urbano-industrial cuja tecnocracia 
dava sentido ao Estado ditatorial e desenvolvimentista pela vinculação da educação às pretensões econômicas. Nesse contexto, além dessa submissão da escola aos ditames econômicos, a dinâmica demográfica experimentada dos anos 1950 a 1990 acentuou as estatísticas de pobreza no Brasil.

$\mathrm{O}$ alto número de analfabetos verificado nesse período aparece como resultado da precariedade do sistema educacional básico brasileiro e do êxodo rural, com a negação do acesso à educação às populações do campo, para as quais a difundida ideologia capitalista atribuía à vida urbana o maior e melhor acesso à educação. A predominante mão-de-obra rural dessas populações não requeria alto grau de especialização, um quadro oportuno para a manutenção do latifúndio e suas mazelas, através do advento da mecanização da produção agrícola que contribuiu para a expulsão dessas populações para as cidades. É valido acrescentar que, já nos anos 1920, era o Ministério da Agricultura, Indústria e Comercio que se responsabilizava pela formação profissional que, por meio desses convênios com os setores produtivos, os cursos podiam ser realizados em instituições de ensino ou não (CUNHA, 2000) mobilizando a formação segundo a conveniência dos setores produtivos associados.

Por seu lado, o crescimento da urbanização e industrialização brasileiras, também demandava mão-de-obra que acreditasse no efetivo desenvolvimento econômico a partir do paradigma urbano-industrial. Nesse contexto, no início da década de 1970, o governo Médici implantou um programa de alfabetização (através do Movimento Brasileiro de Alfabetização - MOBRAL, órgão específico criado e autorizado por decreto federal publicado em 1967) como tentativa de atenuar os índices de analfabetismo. Este sistema baseava-se na leitura, escrita e na realização de pequenas operações matemáticas, institucionalizando uma proposta de alfabetização restrita ao reconhecimento de letras e números, que é uma das ações políticas mais caraterísticas do período militar no Brasil. Com isso, o governo objetivava suprimir a proposta da pedagogia/método Paulo Freire que, desde o início da década de 1960, despontava como forma de resistência à ditadura pela adoção do ensino a partir das palavras geradoras e da problematização do cotidiano. De acordo com Furlan (2013, p. 03), durante a ditadura civil-militar no Brasil a educação foi marcada "por um contexto político social de violência institucional, mediado por uma realidade autoritária imposta pelos militares e pelos setores civis que os apoiavam".

A década de 1970 marca a consolidação urbano-industrial do Brasil, cuja relação com a educação pública e a classe trabalhadora buscava, primordialmente, o atendimento às 
demandas do capital industrial, estendendo-se pelas décadas de 1980 e 1990. Nesse sentido, a proposta de alfabetização restrita ao reconhecimento das letras e números inseria, nos cursos técnicos implantados pelo governo, uma população que, por sua formação e demandas objetivas, se sujeitava às relações de trabalho impostas pela acumulação internacional de capitais e constituía o exército de reserva demandado. Para Furlan (2013, p. 02), a década de 1970 inicia um período em que, em particular,

a classe trabalhadora foi vista como a que poderia realizar efêmeros e deficientes cursos técnicos que suprissem a demanda industrial que se avolumava. A educação voltada aos trabalhadores objetivava a formação de mão-de-obra para ocupar inúmeros postos de trabalho. Portanto, era condição necessária ao atendimento do mercado a formação de um exército de reserva com um mínimo de formação profissional.

Assim, as décadas de 1970 e 1980 foram, particularmente, comprometidas com a urbanização e industrialização do Brasil, interferindo na dinâmica populacional com a intensificação dos fluxos do êxodo rural e das migrações do Norte e Nordeste para o Sudeste como também pela interferência direta nos programas educacionais de alfabetização e formação técnico profissionalizantes.

O final da década de 1980 foi marcado pela “tecnicização"/profissionalização do curso de $2^{\circ}$. Grau, o atual ensino médio. No curso da chamada "década perdida", em meio a crises econômicas, que impactavam o poder aquisitivo da população pelas altas taxas de inflação e desemprego, e diante "transição para a democracia" o discurso da formação técnica permitiu ao Estado brasileiro atribuir aos próprios trabalhadores a responsabilidade sobre sua inserção no mercado de trabalho. Nessas circunstâncias, o fim da década de 1980 já anunciava a "malvadez neoliberal" (FREIRE, 1996) pairando sobre o Estado brasileiro. A "Cefetização" das escolas técnicas efetivada pela lei 6.545/1978 transformou, primeiramente, as escolas técnicas do estado do Rio de Janeiro, Minas Gerais e Paraná em CEFET (Centro Federal de Educação Tecnológica), tendo como principal objetivo a separação entre essas escolas e as universidades. Tal cisão objetivava a oferta de cursos superiores de base tecnológica por parte dos CEFETs, e o atendimento às demandas de mercado também na oferta de cursos técnicos mais adequados e específicos ao estágio de desenvolvimento produtivo brasileiro naquele período (CUNHA, 2000).

Entre os objetivos da Lei 6.545/1978 especificados pelo decreto 87.310/1982, estão o “oferecimento do ensino superior em continuidade ao ensino técnico de $2^{\circ}$. Grau, diferenciado 
do sistema universitário" e "a ênfase na formação especializada, levando em conta as tendências do mercado de trabalho e do desenvolvimento do país" (CUNHA, 2000, p. 209). O autor afirma que o caráter tomado pelos CEFETs, é o de reprodução ampliada da dualidade dos saberes, tendendo para a separação entre a produção do conhecimento e o manejo das tecnologias.

Os últimos anos da década de 1980, também foram marcados pela reforma constitucional para a qual já se encaminhava tanto no ambiente político-institucional quanto nas mobilizações sociais (envolvendo pesquisadores e trabalhadores da educação) uma discussão sobre as diretrizes e bases da educação determinadas pela Lei N. ${ }^{\circ}$ 4.024, de 1961, sobretudo formando nos movimentos sociais e mobilizações de pensadores e profissionais da educação a corrente "estatista" que defendia a autonomia dos sistemas de ensino e o papel político-pedagógico da escola. A mais recente lei de diretrizes e bases da educação No ${ }^{\circ}$ 9.394, promulgada em 1996 (também como produto de mobilização social), no entanto, manteve em seu texto muito do princípio desenvolvimentista, embora defina melhor o papel da escola, o perfil do profissional de educação e a possibilidade de elaborar o seu projeto políticopedagógico.

No que diz respeito à educação profissional, tanto a lei de 1961 quanto a de 1996 preveem o ensino técnico em diversos níveis, incluindo o ensino médio/2. ${ }^{\circ}$ grau. Ao chegar o ano de 1997, o Decreto Federal N. ${ }^{0} 2.208$ veio corroborar a adoção do ensino técnico como transição entre a escola e o mundo do trabalho de forma separada, eliminando a formação técnica do nível médio do ensino. Na análise de Ciavatta et al. (2005) sobre as intenções e efeitos do decreto 2.208/1997, trata-se de uma "regressão social e educacional sob a égide do ideário neoconservador ou neoliberal e da afirmação e ampliação da desigualdade de classes e do dualismo na educação". Ao permitir a formação técnica separadamente e após o ensino médio, essa legislação mantém o restrito acesso da população pobre à universidade, uma vez que o estudante oriundo da classe trabalhadora precisa se inserir e priorizar o mundo do trabalho ainda no decorrer de sua formação educacional básica.

No ano de 2004, com o decreto 5.154, o ensino técnico integrado retorna ao ensino médio nas escolas da rede federal. Trata-se de um contexto político de emergência econômica e de demandas de inserção geopolítica do Brasil no cenário da transnacionalização do capital, no qual de destacou o projeto de expansão da rede federal de ensino, conforme exposto nos dados apresentados no quadro 1. Embora, represente também a busca pelo atendimento às 
demandas econômicas, o decreto cujo texto exige "assegurar, simultaneamente, o cumprimento das finalidades estabelecidas para a formação geral e as condições de preparação para o exercício de profissões técnicas" marcou um passo inicial da importante discussão da escola técnica e sua função social. Essa determinação colocou as escolas técnicas diante do ensino integrado como demanda efetiva, mas, sobretudo, como desafio considerando a trajetória dessas instituições e os atrelamentos político-econômicos que interferiram constantemente em seu funcionamento. A "missão" de formar o cidadão “histórico-crítico" apresentada no projeto político pedagógico do IFBA (2013), por exemplo, admite, nas entrelinhas, a necessidade de uma nova proposta de ensino e da ampliação do debate sobre a formação oferecida. Nesse contexto, o conceito de politecnia representa uma grande contribuição para as escolas técnicas, especialmente diante de uma contemporaneidade na qual a difusão da tecnologia perpassa das tarefas mais simples do cotidiano até a produção científica stricto senso.

\section{3- Ensino integrado e politecnia: desafios da educação profissional na atualidade}

A educação profissionalizante, seu modelo escolar e seu histórico estabelecimento em todo o território nacional se consolidaram pelo atrelamento político-econômico à reprodução da lógica de mercado. A influência do Banco Mundial sobre o Estado brasileiro, especialmente na década de 1990, deu força ao desmonte da educação básica, cuja própria lei de base apresenta possibilidade de penetração dos interesses privados em detrimento das mobilizações das "forças historicamente comprometidas com mudanças mais profundas em nossa sociedade" (CIAVATTA e FRIGOTTO, 2005, p. 52) através da educação. Entre os anos de 1990 a 1996, conferências especificas foram realizadas para "avaliar" a educação dos países da periferia do capitalismo em face da realidade "globalizada" que, então, se desvendava. Para Salles e Fidelis (2006),

Seja como for, dirigida aos trabalhadores diretamente ou indiretamente atingidos pelo processo de reestruturação produtiva da produção, em nenhum dos casos a política compensatória do $\mathrm{BM}^{3}$ enfrenta os efeitos da revolução tecnológica e econômica trazidos pelo processo de globalização.

Desta forma, a educação que, para Frigotto e Ciavatta (2003, p. 99), "seria o instrumento fundamental para desenvolver nos indivíduos a capacidade de responder a esses desafios, particularmente a educação média”, é instrumentalizada pelas imposições da reestruturação produtiva. Nessa perspectiva, o decreto $\mathrm{N}^{\circ}$. 2.208/1997, que estabelece 
modalidades do ensino técnico e tecnológico e dá autonomia inclusive de consulta aos empregadores na elaboração dos currículos para algumas dessas modalidades surge, portanto, com a abertura neoliberal em consequência das diretrizes globais para a educação, segundo a orientação de órgãos supranacionais ligados ao Banco Mundial. Tal decreto determina, legalmente, uma "formação geral" separada da formação técnica, expondo a educação básica à generalização, precarização e a uma educação de nível técnico vulnerável às demandas do capital, tanto como proposta de ensino público quanto como empreendimento de caráter privado (Como no exemplo do Sistema $\mathrm{S}^{4}$ ). O decreto ainda permitia que as empresas interferissem diretamente na oferta de cursos técnicos, inclusive determinando a estrutura curricular dos mesmos.

Segundo Ferretti (2002), esse contexto de interferência do capital nos sistemas educacionais, se assenta em quatro pilares de argumentação que, em síntese, correspondem ao atendimento das seguintes demandas: 1) transformações econômicas e elevação da sofisticação tecnológica de caráter global; 2) Análise comparativa empresarial sobre a educação pública, baseando-se em referências de países capitalistas mais avançados; 3) Universalização do ensino básico, o que inclui o ensino médio; 4) A intervenção do empresariado na gestão dos sistemas educacionais, atribuindo ao governo o provimento de custos das escolas e às empresas a determinação da composição curricular e oferta de cursos adequados ao cenário produtivo.

Como resposta à essas demandas, as diretrizes do decreto № 2.208/1997 foram ampliadas pelo decreto $n^{\circ}$ 5.154/ 2004 que regulamenta o $\S 2^{\circ}$ do art. 36 e os artigos de 39 a 41 (sobre a educação profissionalizante) da Lei no 9.394 (diretrizes e bases da educação), de 20 de dezembro de 1996. Assim, no Artigo 2º item II, permite-se a realização do ensino técnico pela "articulação de esforços das áreas da educação, do trabalho e emprego, e da ciência e tecnologia" (BRASIL, 2004), o que demonstra a continuidade da preocupação em adequar a educação profissionalizante e as escolas técnicas aos interesses de mercado. $\mathrm{O}$ decreto 5.154/2004 amplia a abrangência da educação profissional incluindo a educação de jovens e adultos (EJA), o ensino em nível médio (cursos integrados) e a formação tecnológica nos níveis de graduação e pós-graduação. Percebem-se, com isso, os contornos neoliberais e a ideia de "capital humano" conveniente ao estágio recente do capitalismo no Brasil reproduzindo-se também na recente política de expansão da rede federal de ensino. 
O decreto $\mathrm{n}^{\mathrm{o}}$ 5.154/2004 apresenta ainda como premissa a promoção das "aptidões para a vida produtiva e social" e para o "o aproveitamento contínuo e articulado dos estudos" (BRASIL, 2004). A partir destas determinações, os cursos médios de formação geral oferecidos pelos Institutos Federais passam à obrigatoriedade da integração técnica orientando rumo à produção e operação de inovações tecnológicas que se tornaram imprescindíveis ao desenvolvimento econômico.

O debate acerca da politecnia, diante deste panorama, aponta para a apropriação dos recursos tecnológicos como forma e possibilidade de emancipação social. $\mathrm{Na}$ definição apresentada por Saviani (2003, p. 132),

a noção de Politecnia deriva, basicamente, da problemática do trabalho. Nosso ponto de referência é a noção de trabalho, o conceito e o fato do trabalho como princípio educativo geral. Toda a educação organizada se dá a partir do conceito e do fato do trabalho, portanto, do entendimento e da realidade do trabalho.

Nas palavras de Saviani, é entendido o papel central que o trabalho e, portanto, a classe trabalhadora tem na produção. Entretanto, cabe destacar que o autor considera o trabalho como princípio educativo, não como resultado da preparação escolar. Nesse sentido, Saviani (2003, p. 133) destaca ainda que "se é o trabalho que constitui a realidade humana, e se a formação do homem está centrada no trabalho - isto é, no processo pelo qual o homem produz a sua existência -, é também o trabalho que define a existência histórica dos homens". Assim corroboramos com este autor, sobretudo quando afirma que o trabalho consiste, primordialmente, na produção da vida e que a escola deve se fundamentar nessa perspectiva.

Não obstante, Ciavatta et al. (2005) ressaltam que o termo "tecnologia" foi apropriado e aceito como uma concepção "burguesa" de educação, para a qual a adoção destes recursos e o domínio de sua técnica foram transformados em realidades alheias, distantes, impossíveis. Tal apropriação expõe uma perspectiva alienante do trabalho que, no atual estágio de desenvolvimento do capitalismo, considerando o aprimoramento produtivo, propõe a polivalência como uma das características do trabalho "produtivo" contemporâneo. Trata-se, então, da apropriação capitalista do conceito de politecnia, distorcendo-o e atribuindo ao trabalhador a responsabilidade de agregar funções, sob o argumento da competitividade e concorrência no mundo do trabalho.

Na contramão da perspectiva do capital, Saviani (2003, p. 140) define o conceito de politecnia como "domínio dos fundamentos científicos das diferentes técnicas que Revista RBBA $\mid$ Revista Binacional Brasil Argentina 
caracterizam o processo de trabalho produtivo moderno [que] tem como base princípios, determinados fundamentos que devem ser garantidos". Dominar os fundamentos, contudo, significa apropriar-se da força de trabalho como conhecimento e como produção material das condições necessárias ao desenvolvimento da sociedade. Nesse sentido, a politecnia consiste também na apropriação dos recursos do desenvolvimento capitalista como conhecimento na apreensão dos processos que sustentam esse sistema através do trabalho. Conforme Souza Jr. (1999, p. 106),

\begin{abstract}
Enquanto o ponto de vista burguês defende a educação politécnica como meio de preparar mão-de-obra para que possa atender as exigências de expansão do capital ou, quando muito, como preocupação com o desemprego dos trabalhadores - o que não se resolve com esse tipo de medida - cuja condição de proprietários apenas de força de trabalho é para este ponto de vista uma condição natural, para Marx o ensino politécnico surge como meio para que os trabalhadores dominem os fundamentos científicos, teóricos e práticos dos diversos processos de trabalho. Este domínio, por sua vez, deve atuar contra a alienação da atividade de trabalho muito embora por si só não a supere.
\end{abstract}

As indicações de Souza Jr. (1999) acerca da teoria marxista e sua contribuição em pensar a educação como possibilidade de superar a alienação através da politecnia atestam a indissociabilidade entre a produção e a consciência do processo produtivo. Na proposição de Marx, a constituição dessa consciência através da educação se dá pela articulação entre desenvolvimento físico, domínio científico do conhecimento, produção e manejo da tecnologia. Segundo Marx (1982), por educação entendemos três coisas:

1) Educação intelectual. 2) Educação corporal, tal como a que se consegue com os exercícios de ginástica e militares. 3) Educação tecnológica, que recolhe os princípios gerais e de caráter científico de todo o processo de produção e, ao mesmo tempo, inicia as crianças e os adolescentes no manejo de ferramentas elementares dos diversos ramos industriais. Esta combinação de trabalho produtivo pago com a educação intelectual, os exercícios corporais e a formação politécnica elevará a classe operária acima dos níveis das classes burguesa e aristocrática.

Observa-se nas palavras de Marx que a politecnia (em sua obra entendida por educação tecnológica) se apresenta como uma possibilidade libertária por buscar a apreensão do processo produtivo como um todo. Na discussão de Souza Jr. (1999, p. 106) acerca da proposta de educação apresentada por Marx, 
o ensino politécnico somado à ginástica e ao conteúdo intelectual deveria elevar as classes trabalhadoras acima das demais justamente porque combinaria duas dimensões importantes do processo de trabalho ausentes na formação dos filhos da burguesia, a dimensão intelectual e a prática.

Tal elevação da classe trabalhadora através de uma nova proposta de educação que tem a politécnica como princípio, diz respeito à compreensão do papel desta classe no desenvolvimento do sistema capitalista e, portanto, a sua mobilização diante da centralidade do trabalho nesta sociedade. Trata-se da possibilidade de superação dos limites técnicos da produção e do esclarecimento da efetiva distinção entre classe trabalhadora e burguesia: a capacidade de produzir riquezas através do trabalho. Nesse sentido, Engels (2008, p. 39) afirma que

\begin{abstract}
Não se poderia imaginar melhor método de embrutecimento que o trabalho na fábrica, e se apesar de tudo os operários não só salvaram sua inteligência, mas também a desenvolveram e a aguçaram mais do que os outros, isso apenas foi possível pela revolta contra a sua sorte e contra a burguesia. Esta revolta é o único pensamento e o único sentimento que o trabalho lhes permite. E se esta indignação contra a burguesia não se toma o sentimento predominante entre eles, a consequência inevitável é o alcoolismo e tudo o que habitualmente se chama imoralidade.
\end{abstract}

A "revolta" destacada por Engels, muito mais que uma reação puramente raivosa, consiste na apreensão da produção capitalista como produto do trabalho. E do entendimento das relações de trabalho na perspectiva da luta de classes, diante dos níveis de exploração que a rotina do trabalho fabril e o desenvolvimento histórico do capitalismo demandam. Tais implicações podem ser ratificadas na trajetória das escolas técnicas pelo caráter capitalista das intervenções do Estado, por meio dos decretos e leis aqui discutidos.

\title{
4- Considerações finais
}

A realidade dos cursos integrados, por sua novidade, ampliação e complexidade, nos coloca diante da reflexão sobre o movimento do Estado capitalista, no sentido de ampliar suas formas de reprodução através da educação profissional. Diante de uma política nacional de expansão do ensino técnico e das repercussões do capitalismo global sobre as diversas esferas da educação, as escolas técnicas têm um papel estratégico no cenário político-econômico. Desta forma, a análise desse contexto deixa mais inquietações que conclusões. 
A politecnia, em face da educação profissional, principalmente dos cursos integrados, pode desenvolver princípios revolucionários no sentido da superação do tecnicismo e, mais profundamente, da fragmentação do conhecimento e do trabalho. Em primeiro lugar porque não trata apenas da formação profissional, pois oferece os demais componentes educacionais, possibilitando que o aluno tenha maiores perspectivas de formação e aprimoramento científico durante e após a formação. Em segundo lugar, como uma iniciativa possível e necessária, essa concepção educativa permite aos estudantes originários da classe trabalhadora ter acesso à possibilidade da profissionalização sob uma perspectiva mais unitária articulando tecnologia e trabalho. Em terceiro lugar, o ensino integrado, como uma nova possibilidade da educação básica, traz à vista o grande desafio da educação que é superar a divisão do trabalho em intelectual e manual e, no mesmo sentido, apreender nesta distinção produtiva a luta de classes.

A crítica que aqui se tece é a de que a escola técnica atual precisa se aprimorar e autocriticar no sentido de que essa integração do conhecimento impacte como possibilidade de emancipação social, permitindo repensar os valores educacionais. Não se pode negar as lacunas práticas na construção dos cursos integrados, que precisam ser pensadas como resultado de uma integração mecânica da formação geral com a formação técnica: a duração extensa dos cursos técnicos integrados (considerando que estes atendem a um público com faixa etária correspondente ao ensino médio) cuja carga horária é dilatada em função da adoção das bases curriculares técnica e básica (quase sempre trabalhadas distintamente); a decorrente dificuldade em superar a dualidade trabalho intelectual e manual, que se reproduz como conhecimento (exposta na separação entre as disciplinas do currículo comum e técnico); a evasão de alunos na direção do ensino superior, alegando o longo período de permanência nos cursos integrados, que os impede de ingressar o quanto antes na universidade, ou até mesmo nos cursos superiores dos próprios Institutos Federais (ainda que seja para a integração do exército de reserva com maior qualificação profissional); a pouca inserção dos estudantes remanescentes dos cursos integrados no mercado de trabalho como técnicos (que também contribui para a ampliação do exército de reserva daqueles que sequer se inseriram no mundo do trabalho).

Nessa direção, o ensino técnico integrado, que agrega amplas parcelas da juventude em pleno desenvolvimento cognitivo, se pensado a partir da possibilidade da politecnia, abre possibilidades para a efetivação papel social da escola pública. Essa abordagem educacional

\begin{tabular}{l|l} 
Revista RBBA & Revista Binacional Brasil Argentina
\end{tabular} 
coloca em cheque o tecnicismo pela possibilidade de contribuir para a formação de uma população socialmente ativa que se aproprie da educação como algo mais que um diferencial competitivo diante do mercado de trabalho.

\section{Referências}

BRASIL. Lei Nº 4.024 de 20 de Dezembro de 1961. Fixa as Diretrizes e Bases da Educação Nacional. Diário Oficial da União. Brasília: DF, 1961.

. Lei No ${ }^{\circ}$ 6. 545 de 30 de Junho de 1978. Dispõe sobre a transformação das Escolas Técnicas Federais de Minas Gerais, do Paraná e Celso Suckow da Fonseca em Centros Federais de Educação Tecnológica e dá outras providências. Diário Oficial da União. Brasília: DF, 1978.

. Decreto $N^{\circ} .87 .310$ de 21 de Junho de 1982. Regulamenta a Lei $\mathrm{n}^{\circ} 6.545$, de 30 de junho de 1978, e dá outras providências. Diário Oficial da União. Brasília: DF, 1982.

. Lei No 9.394 de 20 de Dezembro de 1996. Estabelece as diretrizes e bases da educação nacional. Diário Oficial da União. Brasília: DF, 1996.

. Decreto $\mathrm{n}^{\mathrm{o}} 2.208$, de 17 de abril de 1997 . Regulamenta o parágrafo $2^{\circ}$ do art. 36 e os art. 39 a 42 da Lei n. 9.394, de 20 de dezembro de 1996, que estabelece as diretrizes e bases da educação nacional. Diário Oficial da União. Brasília: DF, 1997.

Decreto n. 5.478, de 24 de junho de 2005. Institui, no âmbito das instituições federais de educação tecnológica, o Programa de Integração da Educação Profissional ao Ensino Médio na Modalidade de Educação de Jovens e Adultos (PROEJA. Brasília: DF, 2005.

CIAVATTA, M. et al. A gênese do Decreto n. $^{0}$ 5.154/2004: um debate no contexto controverso da democracia restrita. In: FRIGOTTO, G.; CIAVATTA, M.; RAMOS, M. (orgs). Ensino médio integrado: concepções e contradições. São Paulo: Cortez, 2005.

CIAVATTA, M. FRIGOTTO, G. Educação básica no Brasil na década de 1990: Subordinação ativa e consentida à lógica de mercado. Revista Educação e Sociedade, Campinas, vol. 24, n. 82. Abr. 2003. Disponível em $<$ http://www.cedes.unicamp.br $>$. Acesso em Abril, 2013.

CIAVATTA, M. FRIGOTTO, G. RAMOS, M. A política de educação profissional no Governo Lula: um percurso histórico controvertido. Revista Educação e Sociedade, Campinas, vol.26 n ${ }^{\circ} .92$. Out. 2005. Disponível em $<$ http://www.cedes.unicamp.br $>$. Acesso em Abril, 2013.

CUNHA, Luis Antônio. O ensino profissional na irradiação do industrialismo. São Paulo: Brasília: Ed. UNESP, 2000.

ENGELS, Friedrich. A situação da classe trabalhadora na Inglaterra. São Paulo: Boitempo, 2008. 
FERREIRA JR., Amarílio. História da Educação Brasileira: da colônia ao século XX. Coleção UAB - UFSCAR. São Carlos: EdUFSCAR, 2010.

FERRETTI, Celso João. Empresários, Trabalhadores e Educadores: Diferentes olhares sobre as relações trabalho e educação no Brasil nos anos recentes. In LOMBARDI, José Claudinei. SAVIANI, Dermeval. SANFELICE, José Luis. (Orgs.) Capitalismo, Trabalho e Educação. Campinas: UNICAMP, 2002. 2 ${ }^{\mathrm{a}}$ Ed.

FREIRE, Paulo. Pedagogia da Autonomia. Rio de Janeiro: Paz e Terra, 1996.

FRIGOTTO, Gaudêncio. Capital humano e sociedade do conhecimento: concepção neoconservadora de qualidade na educação. Revista Contexto e Educação, Inijuí, ano 9, no 34. Abr/Jun, 1994. Disponível em <https://www.revistas.unijui.edu.br $>$. Acesso em Março de 2013.

2006.

A Produtividade da Escola Improdutiva. 7.ed. São Paulo: Editora Cortez,

. Delírios da razão: crise do capital e metamorfose conceitual no campo educacional. In: GENTILI, P. (Org.) A Pedagogia da Exclusão. Rio de Janeiro: Petrópolis, 2005. 12.ed.

FURLAN, Elisângela. Educação da década de 1970: formação sem informação. Anais da Jornada do HISTEDBR. 11. 2013, Anais. Campinas: EdUnicamp, 2013. Artigos, p. 1-12. Disponível em < http://www.histedbr.fe.unicamp.br>. Acesso em Marco, 2017.

IFBA (Instituto Federal de Educação, Ciência e Tecnologia da Bahia). Histórico. Disponível em: <http://ifba.edu.br>. Acesso em Abril de 2013.

de 2013.

Institucional: Missão. Disponível em: $<$ http://ifba.edu.br $>$. Acesso em Abril

IFC (Instituto Federal Catarinense). Institucional: A história dos institutos federais. Disponível em: <http://ifc.edu.br> . Acesso em Abril de 2013.

MARX, Karl. Instruções aos Delegados do Conselho Central Provisório. Moscovo: Edições Progresso Lisboa, 1982. Disponível em $<$ https://www.marxists.org.br $>$. Acesso em Fevereiro de 2017.

MOURA, Dante Henrique; FILHO, Domingos Leite Lima; SILVA, Mônica Ribeiro. Politecnia e formação integrada: confrontos conceituais, projetos políticos e contradições históricas da educação brasileira. Revista Brasileira de Educação, São Paulo, Vol. 20 n. 63. p. 1053 - 1080. Out-Dez, 2015. Disponível em < http://www.anped.org.br/site/rbe/rbe>. Acesso em Marco, 2017.

SALLES, Fernando Casadei. FIDÉLIS, Sirlene Moreira. Estado, mercado e escola na década de 1990 no Brasil. Revista HISTEDBR (On-line), Campinas, n. 21, p. 171 - 179. Mar. 2006. Disponível em < http://www.histedbr.fe.unicamp.br>. Acesso em Marco, 2017. 
SANTOS, Milton; SILVEIRA, Maria Laura. Brasil: território e sociedade no início do século XXI. São Paulo: Editora Record, 2001.

SAVIANI, Dermeval. O choque teórico da politecnia. Revista Trabalho, Educação, Saúde. 2003, vol.1, n.1. Jan. 2003. Disponível em < www.scielo.br>. Acesso em Julho de 2013.

SERRA, Rodrigo Valente. Desconcentração urbana e oportunidades de trabalho: um estudo da integração dos imigrantes no mercado de trabalho das cidades médias. In: CNPD - I e II Concurso Nacional de Monografias sobre População e Desenvolvimento. Brasília, 1999. Disponível em $<$ http://redbcm.com.br/bibliografia $>$. Acesso em Março de 2017.

SOUZA JR., Justino de. Politecnia e onilateralidade em Marx. Belo Horizonte: Revista Trabalho \& Educação, Belo Horizonte, n. 5, p. 98 - 114, 1996. Disponível em < http://www.portal.fae.ufmg.br>. Acesso em Março, 2017.

\section{Notas}

\footnotetext{
${ }^{1}$ Os geógrafos brasileiros Milton Santos e Maria Laura Silveira propuseram uma nova leitura regional do Brasil a partir da modernização do território, considerando, principalmente, os níveis de urbanização e de aprimoramento tecnológico produtivo. O autor apresenta a regionalização brasileira como "os quatro Brasis": Região Amazônica, Região Nordeste, Região Centro-Oeste e Região Concentrada (que une o Sudeste ao Sul). Esta última, segundo os autores citados (2001), é onde se articulam mais intensamente e se encontra maior continuidade territorial das condições técnicas, científicas e informacionais na economia do país.
}

${ }^{2}$ A desconcentração urbano-industrial se dá pelo movimento de produção e reprodução do espaço, tendo em vista as demandas e contradições da sociedade capitalista. Para Serra (1999, p. 03), trata-se da ampliação das condições de produção para além das regiões metropolitanas, o que inclui cidades de porte médio e pequeno "espaços alternativos à localização das firmas, ou seja, centros urbanos dotados da infraestrutura necessária para o desenvolvimento de atividades dinâmicas e para o escoamento de sua produção em direção aos mercados consumidores".

${ }^{3}$ Banco Mundial (abreviado pelos autores).

${ }^{4} \mathrm{O}$ sistema S, segundo o Senado Federal (2013), é composto de instituições de interesse de mercado e categorias profissionais associadas. São elas: SENAR (Serviço Nacional de Aprendizagem Rural), SENAC (Serviço Nacional de Aprendizagem do Comércio), SESC (Serviço Social do Comércio), SESCOOP (Serviço Nacional de Aprendizagem do Cooperativismo), SENAI (Serviço Nacional de Aprendizagem Industrial), SESI (Serviço Social da Indústria), SEST (Serviço Social de Transporte), SENAT (Serviço Nacional de Aprendizagem do Transporte) e SEBRAE (Serviço Brasileiro de Apoio às Micro e Pequenas Empresas).

5 Segundo Frigotto (1994, p. 385), o conceito de "capital humano" pode ser entendido como "os enfoques economicistas que reduzem a educação a um mero fator de produção". Nesse sentido podemos abarcar na lógica de formação do "capital humano" a subordinação das escolas técnicas a currículos ditados pelas demandas de mercado, impostas pelo capital privado sobre a educação pública e permitido inclusive pelo decreto federal $\mathrm{N}^{\circ}$ 2.208/ 1997. Frigotto (1994, p. 387) atesta ainda que essa concepção de educação/formação caminha no sentido da negação da história e da ideologia. Novas roupagens têm sido dadas à essa concepção diante do capitalismo global: a noção de 'capital humano' vem sendo redefinida e ressignificada pelas noções de sociedade do conhecimento, qualidade total, pedagogia das competências e empregabilidade (FRIGOTTO, 2005). 


\section{Sobre os autores}

Ione dos Santos Rocha. Doutora em Memória, Linguagem e sociedade (PPGLMS) pela Universidade Estadual do Sudoeste da Bahia (UFBA), Mestre em Geografia pela PPGEO Universidade Federal da Bahia, graduada em Geografia pela UESB e Professora de Geografia do IFBA. Compõe o Grupo de Estudos de Ideologia e Lutas de Classes (GEILC/CNPQ).

José Rubens Mascarenhas de Almeida. Pós-doutor pela Universidade Nacional Autónoma do México (UNAM), Doutor em Ciências Sociais pela PUCSP; docente do Departamento de História e do Programa de Pós-Graduação em Memória: Linguagem e Sociedade, ambos da Universidade Estadual do Sudoeste da Bahia. Orientador, Coordenador do GEILC/CNPQ e pesquisador do NEILS (Núcleo de Estudos de Ideologia e Lutas Sociais - PUCSP). 